\title{
Oleate attenuates palmitate-induced endoplasmic reticulum stress and apoptosis in placental trophoblasts
}

\author{
Bryanne N Colvin ${ }^{1}$, Mark S Longtine ${ }^{2}$, Baosheng Chen², Maria Laura Costa ${ }^{2,3}$ and \\ D Michael Nelson² \\ ${ }^{1}$ Department of Pediatrics, ${ }^{2}$ Department of Obstetrics and Gynecology, Washington University School of Medicine, \\ St Louis, Missouri, USA and ${ }^{3}$ Department of Obstetrics and Gynecology, Universidade Estadual de Campinas, \\ Cidade Universitaria Zeferino Vaz, Campinas, Brazil \\ Correspondence should be addressed to B N Colvin; Email: colvin_b@kids.wustl.edu
}

\begin{abstract}
Pre-pregnancy obesity is increasingly common and predisposes pregnant women and offspring to gestational diabetes, pre-eclampsia, fetal growth abnormalities and stillbirth. Obese women exhibit elevated levels of the two most common dietary fatty acids, palmitate and oleate, and the maternal blood containing these nutrients bathes the surface of trophoblasts of placental villi in vivo. We test the hypothesis that the composition and concentration of free fatty acids modulate viability and function of primary human villous trophoblasts in culture. We found that palmitate increases syncytiotrophoblast death, specifically by caspase-mediated apoptosis, whereas oleate does not cause enhanced cell death. Importantly, exposure to both fatty acids in equimolar amounts yielded no increase in death or apoptosis, suggesting that oleate can protect syncytiotrophoblasts from palmitate-induced death. We further found that palmitate, but not oleate or oleate with palmitate, increases endoplasmic reticulum (ER) stress, signaling through the unfolded protein response, and yielding CHOP-mediated induction of apoptosis. Finally, we show that oleate or oleate plus palmitate both lead to increased lipid droplets in syncytiotrophoblasts, whereas palmitate does not. The data show palmitate is toxic to human syncytiotrophoblasts, through the induction of ER stress and apoptosis mediated by CHOP, whereas oleate is not toxic, abrogates palmitate toxicity and induces fat accumulation. We speculate that our in vitro results offer pathways by which the metabolic milieu of the obese pregnant woman can yield villous trophoblast dysfunction and sub-optimal placental function.
\end{abstract}

Reproduction (2017) 153 369-380

\section{Introduction}

Pre-pregnancy body mass index determines pregnancy outcome (Nelson et al. 2010, Flegal et al. 2012), and more than half of pregnant women in the United States are overweight or obese. The latter are at risk for gestational diabetes, pre-eclampsia, Caesarean delivery and stillbirth (American College of Obstetricians and Gynecologists 2013, Marchi et al. 2015). Moreover, infants of obese women are at increased risk for congenital anomalies, macrosomia, birth injury and childhood obesity (American College of Obstetricians and Gynecologists 2013, Marchi et al. 2015). The mechanisms contributing to these adverse outcomes are poorly understood.

Pre-pregnant obese women exhibit abnormal lipid profiles compared to lean controls (Chen et al. 2010b). Saturated fatty acids circulating in obese women commonly have more lipotoxic potential than non-saturated fatty acids (Poitout et al. 2010, Leamy et al. 2013). Palmitate is a saturated fatty acid found in the highest concentration in most diets and oleate is a dominant monounsaturated fatty acid (van Dijk et al. 2009). Notably, obese pregnant women have higher circulating levels of free fatty acid compared to lean controls, commonly showing higher-than-control concentrations of palmitate and oleate (Chen et al. 2010b). Although total concentrations of serum fatty acids influence health (Pilz et al. 2006, Khaw et al. 2012), levels of specific fatty acids and ratios of saturated to unsaturated fatty acids, also influence health (Micha \& Mozaffarian 2010). Although a limited number of studies have investigated serum free fatty acid levels in pregnant women (Villa et al. 2009, Chen et al. 2010b), no studies have yet directly addressed if the relative amounts of specific fatty acid types (e.g., saturated vs unsaturated) are altered in obese pregnant women compared to lean women, or if altered lipid ratios affect pregnancy outcomes.

Palmitate and oleate differentially affect the fate of cells in a way that depends on cell type, substrate 
concentration and ratio of these fatty acids (Miller et al. 2005, Karaskov et al. 2006, Wei et al. 2006). Palmitate, for example, induces apoptotic cell death in multiple cell types, including pancreatic beta cells (Karaskov et al. 2006), cardiac myocytes (Miller et al. 2005) and hepatocytes (Wei et al. 2006). Additionally, palmitate can induce endoplasmic reticulum (ER) stress, and the resultant activation of the ER stress pathway can be the proximate cause leading to apoptosis and cell death (Karaskov et al. 2006, Cunha et al. 2008, Pfaffenbach et al. 2010, Peng et al. 2011, Lu et al. 2012). In contrast, oleate does not induce apoptosis, and, remarkably, can be protective against palmitate-induced apoptosis (Listenberger et al. 2003, Miller et al. 2005, Soumura et al. 2010, Sommerweiss et al. 2013). Several studies have suggested that oleate-mediated protection from palmitate-induced cell death is related to the formation of neutral lipids, such as triglycerides, which are then stored as lipid droplets (Listenberger et al. 2003, Soumura et al. 2010, Thorn \& Bergsten 2010, Peng et al. 2011).

At the interface between two circulations, the placental villus mediates exchange of nutrients, oxygen and wastes between the maternal and fetal circulations. The human placental villus is thereby positioned to be a target for the metabolic effects from the maternal circulation in obese or lean women during pregnancy. Specifically, a multinucleated epithelial layer, called the syncytiotrophoblast, overlies the chorioallantoic villi and is bathed in the maternal blood that circulates through the intervillous space. This microanatomy allows maternal blood fatty acid levels, and the ratios of saturated and unsaturated fatty acids, to directly affect syncytiotrophoblast function and, ultimately, to modify placental function. We tested the hypothesis that the concentration and ratio of palmitate and oleate differentially modulate viability and function of primary cultures of human syncytiotrophoblasts.

\section{Materials and methods}

\section{Isolation and culture of primary human trophoblasts}

The Institutional Review Board of Washington University School of Medicine approved this study, and written informed consent was obtained to utilize the placentas. Primary human trophoblasts were isolated from placentas retrieved immediately after repeat C-section under epidural anesthesia at 39-week gestation, in non-labored, uncomplicated pregnancies, as previously described (Chen et al. 2010a, 2012).

Trophoblasts were cultured at $37^{\circ} \mathrm{C}$ in $5 \% \mathrm{CO}_{2} /$ ambient air in phenol red-free DMEM (GE Life Sciences, Logan, UT, USA) with $20 \mathrm{mM}$ HEPES (pH 7.4) (Sigma), 100 U/ $\mathrm{mL}$ penicillin and $100 \mu \mathrm{g} / \mathrm{mL}$ streptomycin (obtained from the Washington University tissue culture support center). Trophoblasts were plated at a density of $300,000 \mathrm{cells} / \mathrm{cm}^{2}$ in medium supplemented with $10 \%$ fetal bovine serum (FBS)
(Thermo Fisher Scientific), cultured for $4 \mathrm{~h}$ to allow attachment and rinsed thoroughly with medium to eliminate dead cells and villous fragments; this time was designated as time zero of culture. Medium supplemented with 10\% charcoal-stripped FBS was changed each $24 \mathrm{~h}$ during culture. We assayed the effects on trophoblasts for levels of fatty acids that are typical of those present in human serum: $100 \mu \mathrm{M}$ palmitate or oleate, which approximate those found in lean, healthy pregnant women, whereas $200-400 \mu \mathrm{M}$ of these lipids are present in obese individuals (Villa et al. 2009, Chen et al. 2010b).

\section{Fatty acid, tunicamycin and Z-VAD-FMK treatment}

Oleic acid and palmitic acid were purchased from Sigma. Fatty acid micelles were prepared according to Listenberger and Brown (2007), stored at $4^{\circ} \mathrm{C}$ and used within one week of preparation. Cultures were supplemented with 100, 200 or $400 \mu \mathrm{M}$ of oleate, palmitate or an equimolar mixture of these fatty acids (Sigma) for $24 \mathrm{~h}$ prior to harvest for the concentration-dependent studies. Syncytiotrophoblasts were treated with $200 \mu \mathrm{M}$ oleate, $200 \mu \mathrm{M}$ palmitate or with $200 \mu \mathrm{M}$ of each lipid for $0,3,8$ or $24 \mathrm{~h}$ for time-dependent studies. Where indicated, tunicamycin $(5 \mu \mathrm{g} / \mathrm{mL}$, Sigma) or dimethyl sulfoxide (DMSO) vehicle control was added for $24 \mathrm{~h}$ prior to harvest. Where indicated, the pan-caspase inhibitor Z-VADFMK $(20 \mu \mathrm{M}$, BD Biosciences, Franklin Lakes, NJ, USA) or DMSO vehicle control was added one hour prior to and throughout lipid exposure.

\section{Assessment of cell viability}

Culture medium was harvested for lactate dehydrogenase $(\mathrm{LDH})$ released from cells as a marker of global cell death and assessed by CytoTox 96 non-radioactive cytotoxicity assay (Promega) according to the manufacturer's instructions. Results are expressed as relative amount of LDH released into the culture medium in experimental vs control conditions. Cell viability was also assessed using the MTS colorimetric assay (Cell Titer 96 Aqueous One Solution Cell Proliferation Assay; Promega) according to the manufacturer's instructions. Results are expressed as percent cell viability in experimental vs control conditions.

\section{Western blotting}

Trophoblasts cultured in $22 \mathrm{~mm}$ diameter tissue culturetreated plastic plates were rinsed with PBS and lysed with $120 \mu \mathrm{L}$ of RIPA buffer (1\% Nonidet P-40, 0.5\% deoxycholate and $0.1 \%$ SDS in PBS) containing protease and phosphatase inhibitors (Sigma). Samples were sonicated and centrifuged for $10 \mathrm{~min}$ at $4{ }^{\circ} \mathrm{C}$, and the supernatant was transferred to a fresh tube. Proteins were separated by SDS-PAGE, transferred to polyvinylidene difluoride membranes, blocked for $>1 \mathrm{~h}$ at room temperature with $5 \%$ nonfat dry milk in PBST (PBS with $0.05 \%$ Tween 20) and incubated overnight at $4{ }^{\circ} \mathrm{C}$ with primary antibody (Table 1 ) in either 5\% NFDM or 5\% BSA in PBST, as recommended by the manufacturer. Blots were washed with PBST for $30 \mathrm{~min}$ and then incubated for $4 \mathrm{~h}$ with appropriate horseradish peroxidase-conjugated donkey anti- 
Table 1 Antibodies used for Western blotting.

\begin{tabular}{|c|c|c|c|c|c|}
\hline Protein target & Name of antibody & Manufacturer, catalog \# & Species raised in & Concentration & Dilution used \\
\hline Actin & Actin (I-19) & Santa Cruz Biotechnologies, Dallas, TX, \#sc-1616 & Goat & $200 \mu \mathrm{g} / \mathrm{mL}$ & 1:2000 \\
\hline $\mathrm{BiP}$ & $\mathrm{BiP}(\mathrm{C} 50 \mathrm{~B} 12)$ & Cell Signaling Technology, Danvers, MA; \#3177 & Rabbit & $65 \mu \mathrm{g} / \mathrm{mL}$ & 1:1000 \\
\hline CHOP & $\mathrm{CHOP}$ & Proteintech, Chicago, IL; \#15204-1-AP & Rabbit & $373 \mu \mathrm{g} / \mathrm{mL}$ & 1:300 \\
\hline $\begin{array}{l}\text { Cleaved } \\
\text { caspase } 3\end{array}$ & $\begin{array}{l}\text { Cleaved Caspase-3 } \\
\text { (Asp175) (5A1E) }\end{array}$ & Cell Signaling Technology $\# 9664$ & Rabbit & $80 \mu \mathrm{g} / \mathrm{mL}$ & 1:1000 \\
\hline Cleaved PARP & Cleaved PARP (Asp214) & Cell Signaling Technology \#9541 & Rabbit & $35 \mu \mathrm{g} / \mathrm{mL}$ & 1:1000 \\
\hline $\begin{array}{l}\text { Cleaved } \\
\quad \text { cytokeratin } 18\end{array}$ & M30 CytoDEATH & Roche, Indianapolis, IN; \#12140322001 & Mouse & $16 \mu \mathrm{g} / \mathrm{mL}$ & 1:1000 \\
\hline Goat $\lg G$ & $\begin{array}{l}\text { Anti-goat IgG } \\
\text { HRP conjugate }\end{array}$ & Thermo Scientific, Waltham, MA; \#PA1-28664 & Donkey & $2 \mathrm{mg} / \mathrm{mL}$ & 1:5000 \\
\hline Mouse IgG & $\begin{array}{l}\text { Anti-mouse IgG } \\
\text { HRP-linked antibody }\end{array}$ & Cell Signaling Technology \#7076 & Horse & $170 \mu \mathrm{g} / \mathrm{mL}$ & 1:5000 \\
\hline Rabbit IgG & $\begin{array}{l}\text { Anti-rabbit IgG } \\
\text { HRP-linked antibody }\end{array}$ & Cell Signaling Technology \#7074 & Goat & $66 \mu \mathrm{g} / \mathrm{mL}$ & 1:5000 \\
\hline
\end{tabular}

$\mathrm{BiP}$, binding immunoglobulin protein; $\mathrm{CHOP}, \mathrm{C} / \mathrm{EBP}$ homologous protein; PARP, poly(ADP-ribose) polymerase.

goat, horse anti-mouse or goat anti-rabbit IgG antibodies at room temperature. Blots were washed with PBST, and targeted proteins were detected by chemiluminescence (Thermo Scientific). Protein expression levels were determined by densitometry, normalized to actin and quantified using ImageJ software (NIH).

\section{Quantitative real-time PCR}

RNA isolation, cDNA generation and quantitative realtime PCR (qRT-PCR) were done as described previously (Chen et al. 2015). Briefly, nucleic acid was isolated from primary trophoblasts with TRI Reagent (Life Technologies), DNA was removed by DNAse treatment (Turbo DNA-free, Life Technologies) and cDNA generated by reverse transcription using the High Capacity cDNA Reverse Transcription kit (Applied Biosystems) in a $50 \mu \mathrm{L}$ reaction containing $0.5 \mu \mathrm{g}$ RNA, $1 \times$ RT buffer, $50 \mathrm{mM}$ deoxy-NTP, random hexamers at $1 \times$ as recommended by the manufacturer, 0.4 units $/ \mu \mathrm{L}$ RNase inhibitor and 2 units $\mu \mathrm{L}$ MultiScribe reverse transcriptase, at $25^{\circ} \mathrm{C}$ for $10 \mathrm{~min}, 37^{\circ} \mathrm{C}$ for $120 \mathrm{~min}$ and $85^{\circ} \mathrm{C}$ for $10 \mathrm{~min}$. qRT-PCR reactions were carried out in a CFX96 real-time PCR machine (Bio-Rad Laboratories), using $1 \mu \mathrm{L}$ of cDNA with $500 \mathrm{nM}$ each of the forward and reverse gene-specific primers (Table 2) and Universal SYBR green supermix (Bio-Rad Laboratories) in a total reaction volume of $10 \mu \mathrm{L}$. Dissociation curves were evaluated for all reactions to verify amplification of a single product with the appropriate melting temperature. Agarose gel electrophoresis verified the generation of a single product of the expected size for all primer pairs used for qRT-PCR. RNA expression levels were normalized to parallel reactions with primers specific for YWHAZ (Meller et al. 2005, Murthi et al. 2008). The fold increase gene expression in experimental relative to control conditions was determined by utilizing the $2^{-\Delta \Delta \mathrm{Ct}}$ method (Schmittgen \& Livak 2008).

\section{Gene silencing by siRNA}

At $24 \mathrm{~h}$ of culture, trophoblasts were transferred to OPTIMEM with $10 \%$ csFBS and transfected with $50 \mathrm{nM}$ siCTRL or siCHOP RNA (OriGene, Rockville, MD, USA, SR30004, SR301166B) prepared using DharmaFECT 1 (Dharmacon) according to the manufacturer's instructions. After 24-h culture in the transfection medium, medium was replaced with DMEM with vehicle or DMEM with $200 \mu \mathrm{M}$ palmitate and culture was continued for another $24 \mathrm{~h}$ prior to harvest.

\section{Lipid droplet staining}

Primary cultures were fixed with $3 \%$ paraformaldehyde in PBS for $30 \mathrm{~min}$ at room temperature, and then permeabilized and blocked with $0.01 \%$ saponin in 3\% BSA for $45 \mathrm{~min}$ at room temperature. Lipid droplets were stained with BODIPY 493/503 (1:500; Molecular Probes) and nuclei were stained with TOPRO3 ( $1 \mu \mathrm{M}$; Life Technologies) for one hour at room temperature. Images were obtained using a Nikon E800 C1 confocal microscope at $1024 \times 1024 \mathrm{px}$ resolution using a final magnification of $600 \times$. At least four representative areas of syncytiotrophoblasts for each condition from three separate placentas were outlined, and the area was measured using

Table 2 Primers for RT-PCR.

\begin{tabular}{lll}
\hline Gene & Acc. No. & Sequence $\left(5^{\prime}-3^{\prime}\right)$ \\
\hline BCL2 & NM_000633.2 & $\begin{array}{l}\text { F: CGGGAGATGTCGCCCCTGGT } \\
\text { R: CAAAGGCATCCCAGCCTCCGT }\end{array}$ \\
BiP & NM_005347.4 & $\begin{array}{l}\text { F: CGGGCAAAGATGTCAGGAAAG } \\
\text { R: TTCTGGACGGGCTTCATAGTAGAC }\end{array}$ \\
CHOP & NM_001195053.1 & F: ACCAAGGGAGAACCAGGAAACG \\
PUMA & NM_014417 & F: GACCTCAACGCACAGTACGAG \\
XBP1 & NM_005080.3 and & F: CTGGAACAGCAAGTGGTAGA \\
(T) & NM_001079539.1 & R: CTGGGTCCTTCTGGGTAGAC \\
XBP1 & NM_005080.3 & F: CAGCACTCAGACTACGTGCA \\
(US) & & R: ATCCATGGGGAGATGTTCTGG \\
XBP1 & NM_001079539.1 & F: CTGAGTCCGAATCAGGTGCAG \\
(S) & & R: ATCCATGGGGAGATGTTCTGG \\
YWHAZ & NM_001135702.1 & F: TTTGGTACATTGTGGCTTC \\
& & R: CCCGCCAGGACAAACCAG \\
\hline
\end{tabular}

$X B P(\mathrm{~T})$ primers are used to amplify simultaneously both unspliced (NM_005080.3) and spliced (NM_001079539.1) forms of XBP1 mRNA by non-quantitative PCR for analysis by gel electrophoresis. All other primer pairs were used for qRT-PCR.

Acc. No.: NCBI RefSeq nucleotide accession number; $B C L 2$, B-cell lymphoma 2; BiP, binding immunoglobulin protein; $C H O P, \mathrm{C} /$ EBP homologous protein; FOR, forward; PUMA, p53 upregulated modulator of apoptosis; REV, reverse; XBP1, X-box binding protein 1; $Y W H A Z$, tyrosine 3-monooxygenase/tryptophan 5-monooxygenase activation protein, zeta polypeptide. 
Image software (NIH). Lipid droplets and nuclei within these areas were then quantified. Results are presented as number of lipid droplets per unit area.

\section{Statistical analysis}

The number $(n)$ of placentas for each set of experiments is indicated in the figure legend or on the figure. Data are mean \pm S.D. One-way ANOVA with Bonferroni post hoc test for $\geq 3$ conditions or Student's $t$-test for two comparisons was performed using KaleidaGraph software (Synergy Software, Reading, PA, USA).

\section{Results}

\section{Palmitate, but not oleate, decreases syncytiotrophoblast viability}

Primary cytotrophoblasts fuse beyond $24 \mathrm{~h}$ in culture and $>85 \%$ of nuclei are in syncytiotrophoblasts by $52 \mathrm{~h}$, as we previously described (Wang et al. 2016). Primary cultures exposed to 200 or $400 \mu \mathrm{M}$ palmitate for $24 \mathrm{~h}$ showed significantly increased levels of $\mathrm{LDH}$ in the culture medium, compared to vehicle control (Fig. 1A and B). This effect was time dependent, with LDH significantly increased above control after $24 \mathrm{~h}$ of exposure (Fig. 1B). In contrast, oleate did not result in increased LDH levels in the medium, even after $24 \mathrm{~h}$ of exposure to $400 \mu \mathrm{M}$ (Fig. 1A and B). Notably, syncytiotrophoblasts exposed to an equimolar mixture of oleate and palmitate showed $\mathrm{LDH}$ release is indistinguishable from that of control or oleate-only exposed cells and significantly less than that in palmitate-only exposed cultures (Fig. 1A and B). Together, these data indicate that palmitate, but not oleate, is cytotoxic for syncytiotrophoblasts, and that oleate can protect syncytiotrophoblasts from palmitateinduced cell death.

\section{Palmitate, but not oleate, induces syncytiotrophoblast apoptosis}

We next sought to determine whether palmitateinduced cell death occurred via apoptosis. We found that syncytiotrophoblasts exposed to palmitate, but not to oleate, showed elevated levels of the cleaved, active form of the effector caspase, caspase 3, compared to control (Fig. 2). This activation depended on the palmitate concentration and length of exposure (Fig. 2A and B). We buttressed these results by assay of palmitate-exposed syncytiotrophoblasts for cleaved poly(ADP-ribose) polymerase (PARP) (cl-PARP), a nuclear-localized marker of caspase-mediated apoptosis, and for cleaved cytokeratin 18 (cl-CYT18), a caspase substrate in the cytoplasm. Compared to control, both markers of apoptosis showed higher levels of cleaved substrates in palmitate-treated cultures compared to control cells, in agreement with the increase of active caspase 3 (Fig. 2A and B). In contrast,
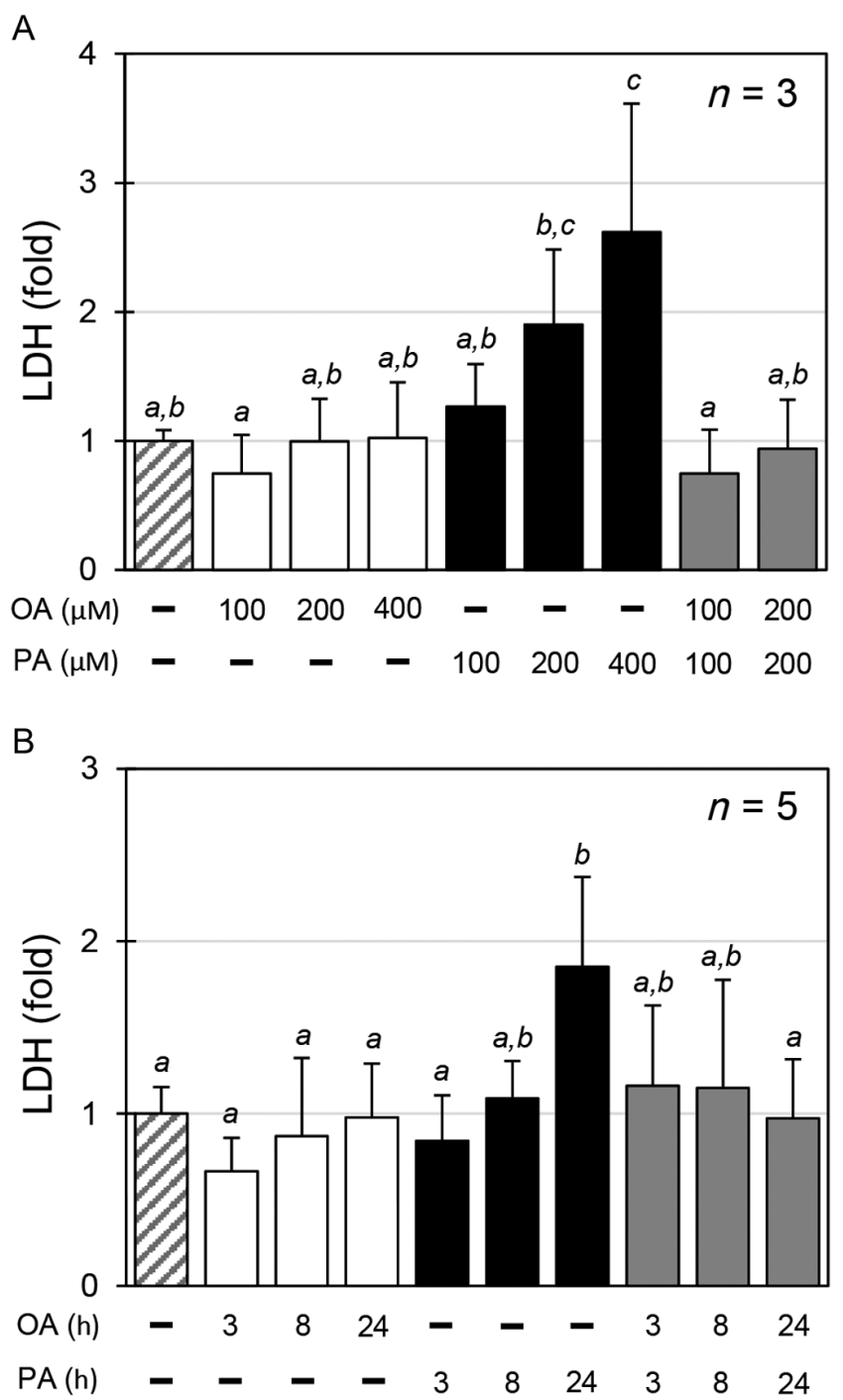

Figure 1 Palmitate, but not oleate or palmitate with oleate, increases syncytiotrophoblast LDH release. Media LDH levels were quantified as a marker of cell death and are expressed as fold change from control with no added lipid. (A) Syncytiotrophoblasts were treated with oleate or palmitate at increasing concentrations or with equimolar concentrations of both lipids, for $24 \mathrm{~h}$.

(B) Syncytiotrophoblasts were treated with $200 \mu \mathrm{M}$ oleate,

$200 \mu \mathrm{M}$ palmitate or with $200 \mu \mathrm{M}$ of each lipid, for the indicated times. Data are mean \pm S.D. with the number of primary cultures indicated by $n$. Conditions with a common italicized letter do not differ as analyzed by one-way ANOVA with Bonferroni post hoc test $(P<0.05)$.

there was no effect of oleate compared to control for the activation of caspase 3 or on the levels of cl-PARP or cl-CYT18 (Fig. 2A and B). Moreover, co-incubation of syncytiotrophoblasts with oleate and palmitate at equimolar concentrations prevented both the activation of caspase 3 and caspase-mediated cleavage of PARP and cytokeratin 18 (Fig. 2A and B). Collectively, these data indicate that palmitate, but not oleate, induces caspase-mediated death of syncytiotrophoblasts and that oleate reduces palmitate-induced apoptosis. 
A
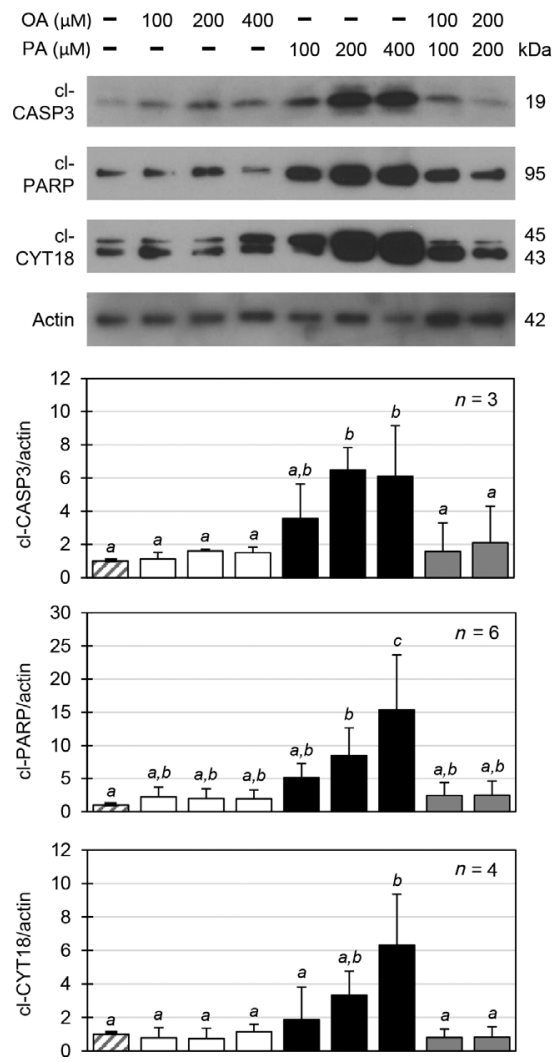

\section{$\mathrm{B}$}
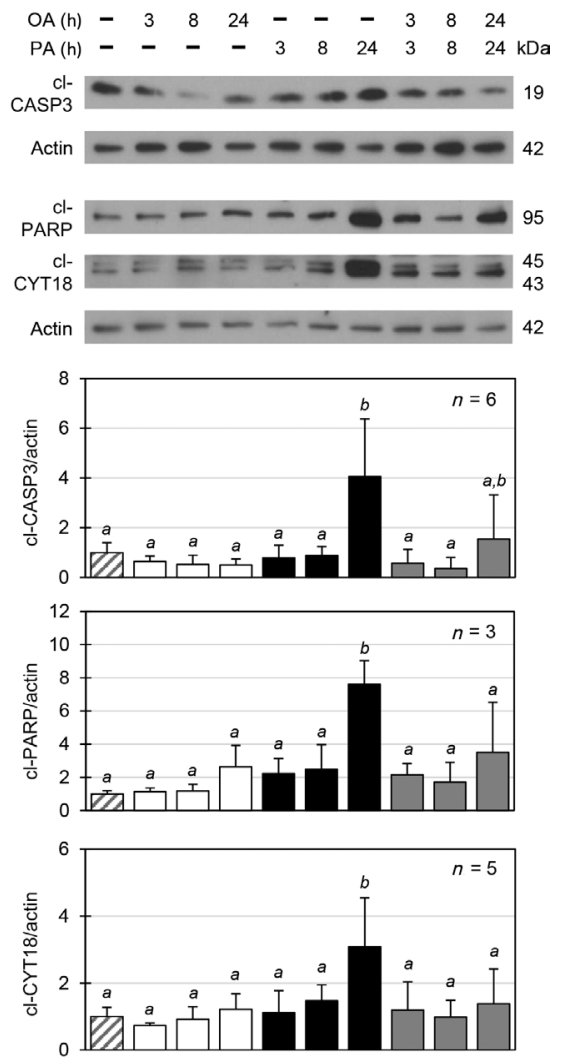

Figure 2 Palmitate, but not oleate or palmitate with oleate, increases caspase activation and apoptosis in syncytiotrophoblasts. (A and B) Top panels, representative Western blots of active (cleaved) caspase 3 (cl-CASP3), cleaved PARP (cl-PARP) and cleaved cytokeratin 18 intermediate filaments (cl-CYT18); bottom panels, quantified protein levels normalized to actin. (A) Syncytiotrophoblasts were treated with oleate or palmitate at increasing concentrations for $24 \mathrm{~h}$. (B) Syncytiotrophoblasts were treated for the indicated times with $200 \mu \mathrm{M}$ oleate, $200 \mu \mathrm{M}$ palmitate or with $200 \mu \mathrm{M}$ of each lipid. Data are mean \pm S.D. with the number of primary cultures indicated by $n$. Conditions with a common italicized letter do not differ as analyzed by one-way ANOVA with Bonferroni post hoc test $(P<0.05)$.

\section{Palmitate activates caspase-mediated apoptosis}

Palmitate may induce cell death independent of caspasemediated apoptosis (El-Assaad et al. 2003) or through alternative pathways (Schilling et al. 2013). We thus determined if caspase activity was required for palmitateinduced syncytiotrophoblast death. We found that the pan-caspase inhibitor Z-VAD-FMK prevented caspase activity in response to palmitate exposure, as indicated by reduced levels of cl-PARP (Fig. 3A) and Cl-CYT18 (Fig. 3B). Z-VAD-FMK also reduced LDH release (Fig. 3C) and enhanced cell viability by MTS assay (Fig. 3D) in palmitate-exposed syncytiotrophoblasts, compared to cells exposed to palmitate in the absence of Z-VAD-FMK. Together, these data indicate that palmitate-enhanced apoptosis and cell death of syncytiotrophoblasts occurs through a caspase-mediated pathway.

\section{Palmitate, but not oleate, increases endoplasmic reticulum stress in syncytiotrophoblasts}

ER stress occurs when cellular alterations lead to accumulation of misfolded proteins in the ER. This activates a series of cellular pathways known as the unfolded protein response (UPR), which is mediated by three main stress sensors expressed at the ER membrane: PKR-like ER kinase (PERK), inositolrequiring transmembrane kinase/endonucleases
(IRE $1 \alpha$ and $\beta$ ) and activating transcription factor 6 (ATF6) (Dufey et al. 2014). We tested the hypothesis that palmitate-induced apoptosis was mediated by ER stress in syncytiotrophoblasts. We found that palmitatetreated syncytiotrophoblasts showed higher than control mRNA and protein levels of binding immunoglobulin protein (BiP/GRP78/HSPA5), a chaperone for misfolded proteins in the ER (Fig. 4A and C). Notably, BiP mRNA and protein levels were not increased after exposure to either oleate or the combination of oleate and palmitate (Fig. 4A and C).

As a positive control, we exposed syncytiotrophoblasts for $24 \mathrm{~h}$ to tunicamycin, a well-characterized inducer of ER stress (Finnie 2001, Xu et al. 2005, Tabas \& Ron 2011) and analyzed the expression of spliced and unspliced forms of $X$-box-binding protein 1 (XBP1). The spliced form of $X B P 1(X B P 1 s)$ encodes a transcription factor, and $X B P 1$ splicing is induced downstream of activation of IRE1 $\alpha$ after the induction of ER stress (Dufey et al. 2014). As expected, and consistent with the work of others on tunicamycin-induced ER stress in trophoblasts (Yung et al. 2008, 2012a,b), we found that tunicamycin yielded an $9.5 \pm 2.1$-fold increase in $X B P 1 s$ levels $(n=6, P<0.05$, Student's $t$-test) compared to vehicle control. Additionally, tunicamycin-exposed trophoblasts also exhibited a $\sim 50 \%$ increase in $\mathrm{LDH}$ release compared to vehicle control $(n=6, P<0.05$, Student's $t$-test). Similar to tunicamycin, palmitate also 

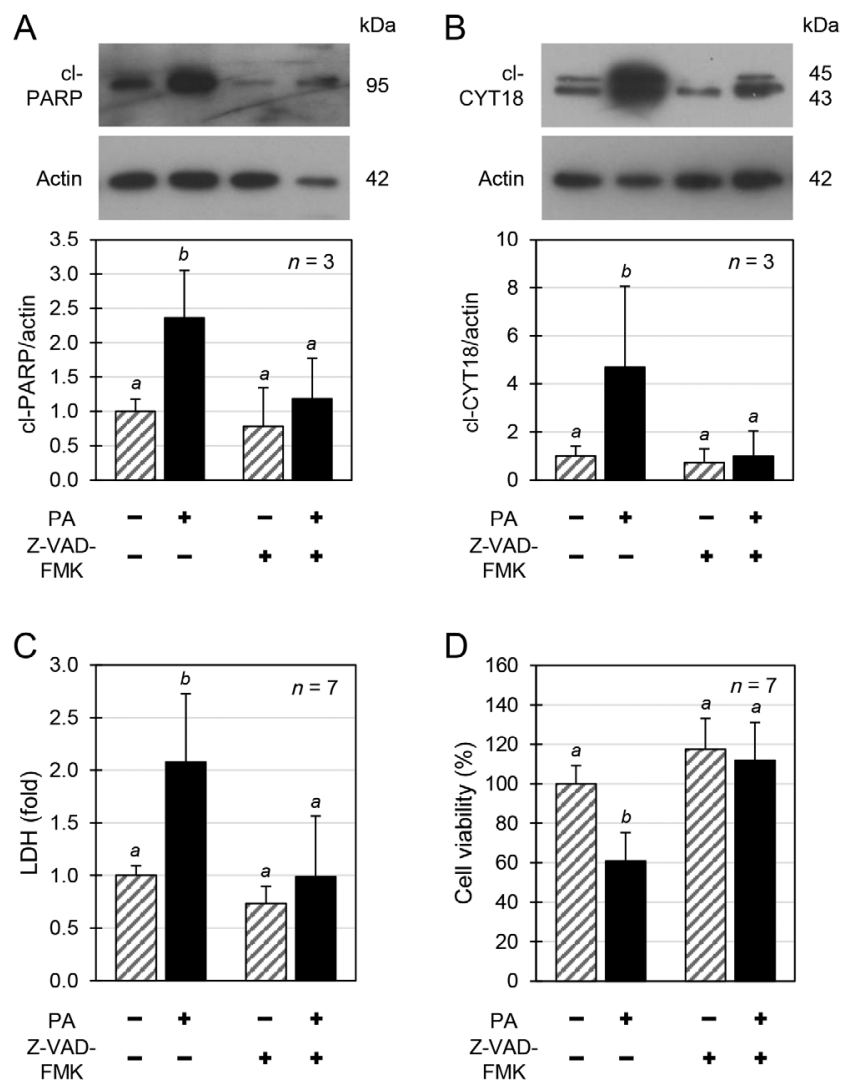

Figure 3 Palmitate-increased cell death requires caspase activity. (A, B, C and D) Syncytiotrophoblasts were treated without or with $200 \mu \mathrm{M}$ palmitate for $24 \mathrm{~h}$ in the absence or presence of $20 \mu \mathrm{M}$ Z-VAD-FMK. (A and B) Top panels, representative Western blots of Cl-PARP and Cl-CYT18; bottom panels, quantified protein levels, normalized to actin. (C) Media LDH levels were quantified as a marker of cell death and are expressed as fold change from vehicle control. (D) Syncytiotrophoblast viability was assessed by MTS assay and is expressed as percent viability compared to control with no added lipid and without Z-VAD FMK. Data are shown as mean \pm S.D. with the number of primary cultures indicated by $n$. Conditions with a common italicized letter do not differ as analyzed by one-way ANOVA with Bonferroni post hoc test $(P<0.05)$.

resulted in increased $X B P 1$ splicing, as assayed by both qRT-PCR (Fig. 4A) and gel electrophoresis of products using primers that simultaneously amplify both XBP1s and $X B P 1$ us (Fig. 4B). In contrast, oleate did not induce $X B P 1$ splicing (Fig. 4A and B). Remarkably, co-exposure of cells to oleate and palmitate also did not yield increased XBP1 splicing (Fig. 4A and B). Together, these data show that palmitate increases $X B P 1$ splicing by syncytiotrophoblasts (Fig. 4B), whereas oleate does not and that oleate can reduce or prevent palmitate-induced XBP1 splicing.

We next pursued the effects of palmitate exposure on C/EBP homologous protein (CHOP/GAD153/ DDIT3). Importantly, $\mathrm{CHOP}$ is a downstream target for both PERK and activating transcription factor 4 (ATF4) (Hockenbery et al. 1993, Dufey et al. 2014), and we found $\mathrm{CHOP}$ mRNA and protein expression was higher than control in palmitate-treated cultures (Fig. 4A and C). CHOP links ER stress to the induction of apoptosis (Tabas \& Ron 2011, Urra et al. 2013) via CHOPmediated reduction in levels of the anti-apoptotic protein B-cell lymphoma 2 (BCL2) (Hockenbery et al. 1993) and CHOP-mediated increased mRNA expression of the pro-apoptotic p53-upregulated modulator of apoptosis (PUMA) (Urra et al. 2013). As would be predicted, palmitate decreased mRNA levels of $B C L 2$ and enhanced the levels of mRNA for PUMA in human syncytiotrophoblasts (Fig. 4A). Notably, we found an increased level of CHOP protein after $8 \mathrm{~h}$ of palmitate exposure (Fig. 4C), whereas clear induction of apoptosis required $24 \mathrm{~h}$ (Fig. 2B), indicating that $\mathrm{CHOP}$ expression precedes apoptosis induction in palmitateexposed syncytiotrophoblasts. These results contrasted with results where syncytiotrophoblasts were exposed to oleate alone, to equimolar concentrations of oleate and palmitate, or to vehicle control, where there was no change in expression of mRNA for XBP1s, XBP1us, $C H O P, B C L 2$ or $P \cup M A$ (Fig. 4A) or expression of protein for $\mathrm{BiP}$ or $\mathrm{CHOP}$.

\section{CHOP mediates palmitate-induced apoptosis}

We next tested the hypothesis that $\mathrm{CHOP}$ mediates the induction of apoptosis by palmitate. Exposure of syncytiotrophoblasts to silencing RNA (siRNA) specific for $\mathrm{CHOP}$ (siCHOP) for $24 \mathrm{~h}$ prior to exposure to $200 \mu \mathrm{M}$ palmitate for $24 \mathrm{~h}$ reduced the induction of CHOP mRNA level 86\% compared to siCTRL (Fig. 5A). Moreover, siCHOP exposure under these conditions resulted in a $\sim 65 \%$ reduction in $\mathrm{CHOP}$ protein level (Fig. 5B). Importantly, the reduction of $\mathrm{CHOP}$ reduced the expression of both markers of apoptosis, cl-PARP and $\mathrm{Cl-CYT} 18$, by $35 \%$ and $60 \%$ respectively (Fig. 5B). Consistent with these findings, siCHOP also reduced $\mathrm{LDH}$ release in palmitate-exposed cells (Fig. 5C). Collectively, these data indicate that $\mathrm{CHOP}$ activation plays a significant role in palmitate-induced apoptotic cell death of placental syncytiotrophoblasts, although non-CHOP-mediated events may also be involved.

\section{Oleate, but not palmitate, enhances lipid droplet formation in syncytiotrophoblasts}

We sought to determine why oleate, unlike palmitate, did not trigger cell death in human syncytiotrophoblasts. As lipid droplet formation avoids cell toxicity (Cnop et al. 2001, Listenberger et al. 2003, Mantzaris et al. 2011), we investigated the induction of lipid droplet formation in response to each of the two free fatty acids. Notably, numbers (Fig. 6A and C) and size (data not shown) of lipid droplets increased in trophoblasts exposed to increasing 
A
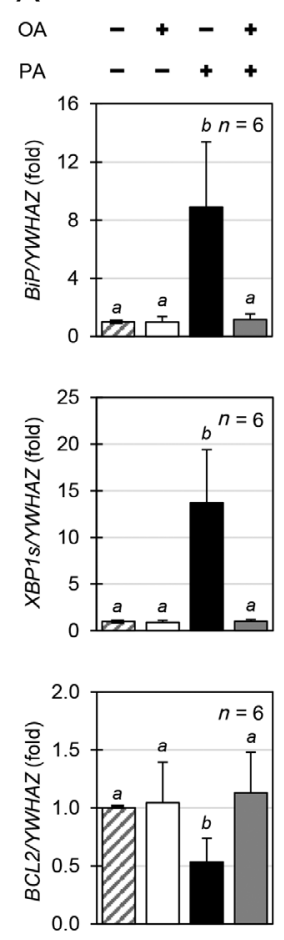
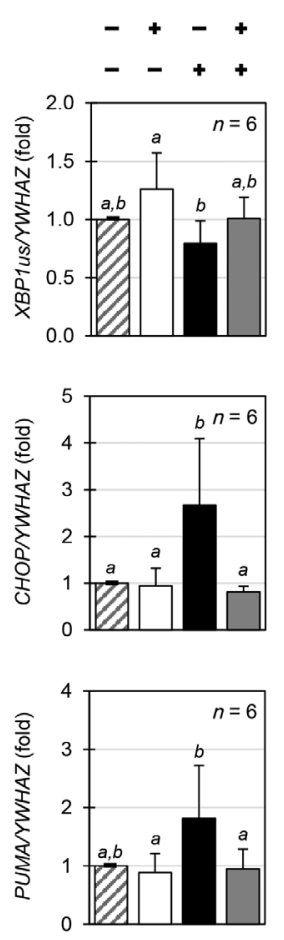

\section{B}

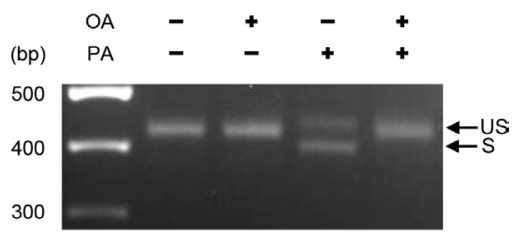

C

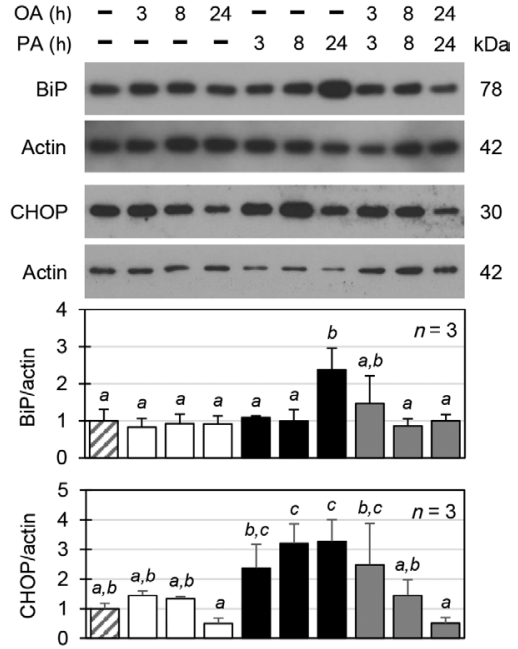

Figure 4 Palmitate, but not oleate or palmitate with oleate, induces ER stress in syncytiotrophoblasts. (A and B)

Syncytiotrophoblasts were treated with $200 \mu \mathrm{M}$ oleate, palmitate or $200 \mu \mathrm{M}$ of each lipid for $24 \mathrm{~h}$. (A) Quantitative RT-PCR was performed and expression was normalized to $Y W H A Z$ as a stable reference gene. (B) Agarose gel electrophoresis of quantitative real-time PCR (qRT-PCR) products of XBP1 splice forms after treatment with vehicle control or the indicated lipids. (C) Syncytiotrophoblasts were treated with $200 \mu \mathrm{M}$ oleate, palmitate or $200 \mu \mathrm{M}$ each for the indicated times. Top panels, representative Western blots of binding immunoglobulin protein (BiP) and C/EBP homologous protein (CHOP); bottom panels, quantified protein levels normalized to actin. Data are mean \pm S.D. with the number of primary cultures indicated by $n$.

Conditions with a common italicized letter do not differ as analyzed by one-way ANOVA with Bonferroni post hoc test $(P<0.05)$. concentrations of oleate, with a 17 -fold increase in numbers after exposure to $400 \mu \mathrm{M}$, compared to control (Fig. 6A and C). As expected, lipid droplet formation was time dependent, detectable after $3 \mathrm{~h}$ of incubation with oleate and increased further with additional time of exposure (Fig. 6B and D). In contrast, palmitate neither increased nor decreased lipid droplet number (Fig. 6A, B, C and D) or diameter (data not shown) under any condition assayed, compared to vehicle control. Moreover, cells exposed to equimolar levels of oleate and palmitate yielded lipid droplet formation in a dose- and time-dependent manner (Fig. 6A, B, C and D). These data indicate that lipid droplet formation in syncytiotrophoblasts is induced by oleate, but not palmitate.

\section{Discussion}

The data show that palmitate is lipotoxic for syncytiotrophoblasts and induces apoptosis in these unique cells through a caspase-mediated pathway involving ER stress, unfolded protein response and increased expression of the transcription factor $\mathrm{CHOP}$. Our data also show that oleate is not lipotoxic, either alone or in combination with palmitate, and this unsaturated fatty acid provides protection from lipotoxicity by formation of lipid droplets in syncytiotrophoblasts.

Our results indicate that palmitate-mediated induction of prolonged ER stress induces apoptosis of trophoblasts, in agreement with the findings in other systems (Miller et al. 2005, Karaskov et al. 2006,
Wei et al. 2006, Lai et al. 2008). However, mechanisms in addition to, or instead of, elevated ER stress have been proposed for palmitate-induced lipotoxicity in non-trophoblast systems, including ceramide synthesis and formation of mitochondrial reactive oxygen species (Yuzefovych et al. 2010) and alterations in calcium homeostasis (Egnatchik et al. 2014). We recognize that ER stress is likely not the sole mechanism of palmitate-mediated lipotoxicity of syncytiotrophoblasts. Further work will be required to investigate these important issues.

Also, as an area for future investigation, it will be of interest to determine whether non-stoichiometric (sub-equimolar) levels of oleate may be able to reduce saturated fat-induced lipotoxicity in trophoblasts, as has been found in some other systems (Mantzaris et al. 2011, Leamy et al. 2014). The ratios of saturated vs unsaturated fatty acids on in vitro and in vivo lipotoxicity also merit further investigation.

In this study, we examined the effects of one saturated (palmitate) and one unsaturated (oleate) fatty acid on trophoblast viability. These were chosen because they are the most prevalent fatty acids present in the circulation and due to the need to keep the system experimentally tractable. However, the in vivo situation is clearly more complex, with multiple types of fatty acids being present. Several previous studies (Akazawa et al. 2010, Thorn \& Bergsten 2010, Mantzaris et al. 2011, NemcovaFurstova et al. 2011, Kwon et al. 2014) that investigated different dietary fats have found that the other prevalent dietary saturated fat, stearate and several dietary 
A

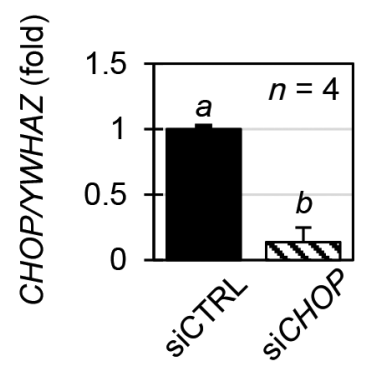

B
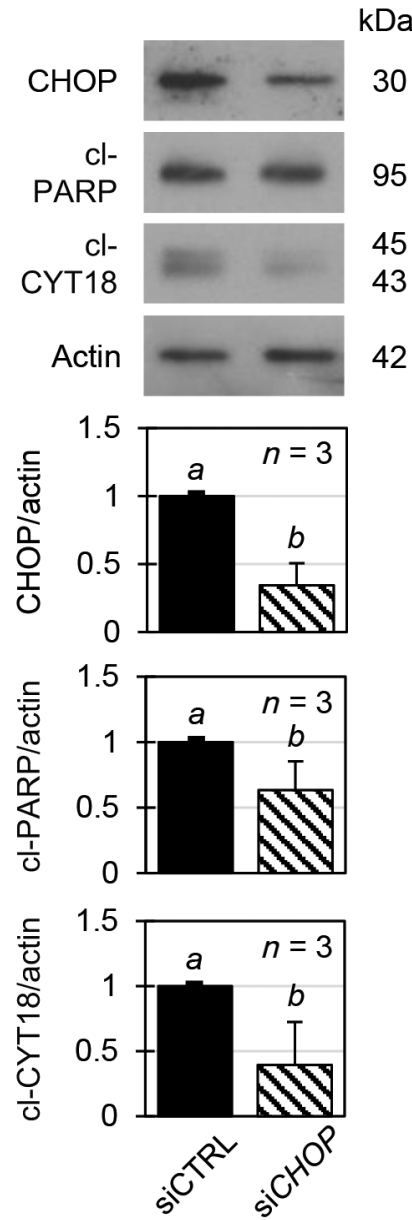

C

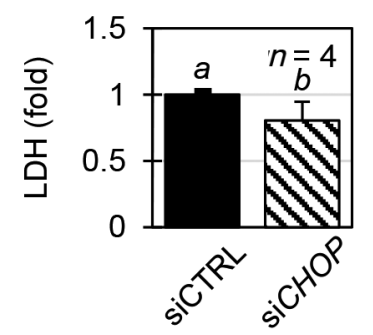

Figure $5 \mathrm{CHOP}$ mediates palmitate-induced apoptosis. (A, B and C) Syncytiotrophoblasts were treated with $50 \mathrm{nM}$ of siCTRL or siCHOP for $24 \mathrm{~h}$ then with $200 \mu \mathrm{M}$ palmitate for $24 \mathrm{~h}$. (A) Quantitative RT-PCR was performed and expression was normalized to $Y W H A Z$ as a stable reference gene. (B) Top panels, representative Western blots of $\mathrm{CHOP}$, Cl-PARP and cl-CYT18; bottom panels, quantified protein levels unsaturated fats, including linoleate, palmitoleate, eicosapentaenoic acid and docosahexaenoic acid, have lipotoxic or lipoprotective effects respectively, similar to what was observed in our study. Thus, it is important to note that the ratio of saturated to unsaturated serum fatty acids, rather than just the total levels of fatty acids, may be a very important in regard to lipotoxicity. Our work suggests that detailed evaluation of the relative serum levels and ratios of saturated vs unsaturated fatty acids in lean vs obese pregnant women would be worthwhile.

Our data also show that oleate, with or without the addition of palmitate, increased lipid droplet formation in syncytiotrophoblasts. We speculate that this offers a potential mechanism for the cytoprotective effect of oleate against palmitate-induced lipotoxicity. Several other studies of how unsaturated fats protect against saturated fat lipotoxicity have suggested several mechanisms (Guo et al. 2007, Kwon et al. 2014, Palomer et al. 2014), including an increase in neutral lipid formation in the form of triglycerides (Listenberger et al. 2003) via induction of the enzyme diacylglycerol acyltransferase (Soumura et al. 2010, Thorn \& Bergsten 2010), thus preventing formation of compounds such as diacylglycerol, which can cause cellular damage through the induction of ER stress. Indeed, although we have shown several downstream markers of ER stress, including XBP1, BiP and $\mathrm{CHOP}$, we have not investigated upstream markers, such as ATF6 cleavage, PERK phosphorylation or eukaryotic initiation factor 2 alpha (elF2 $\alpha$ ), which merit investigation of future work. We do note, however, that there is a significant amount of overlap in the downstream targets of all three UPR pathways (Tabas \& Ron 2011, Hetz 2012, Urra et al. 2013).

Fatty acids are obviously important for fetal development, as they provide a framework for all cell membranes and they are indispensable for most organ development, especially the brain. Notably, maternal blood oleate and palmitate constitute more than half of the nonesterified free fatty acids (FFA) in the maternal circulation (Villa et al. 2009). These two FFA differentially regulate trophoblast amino acid transport. Oleic acid stimulates system A amino acid transport through toll-like receptor 4 (Lager et al. 2013), and oleic acid increases the phosphorylation of multiple pathways to affect placental function, including ERK, mTOR, S6 kinase 1 and rpS6 signaling (Lager et al. 2014). Interestingly, palmitic acid does not affect amino acid transport but does reduce $\mathrm{I} \mathrm{B} \alpha \alpha$, predisposing to the inflammatory state typical of obese pregnant women

normalized to actin. (C) Media LDH levels were quantified as another marker of cell death and are expressed as fold change from control with siCTRL. Data are mean \pm s.D. with the number of primary cultures indicated by $n$. Conditions with a common italicized letter do not differ as analyzed by Student's $t$-test $(P<0.05)$. 
A
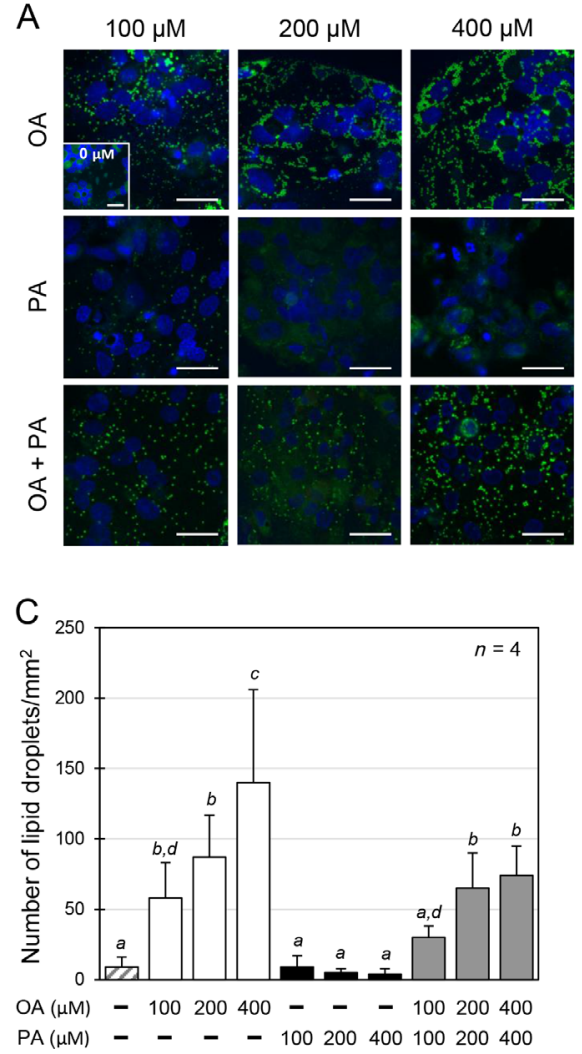

B
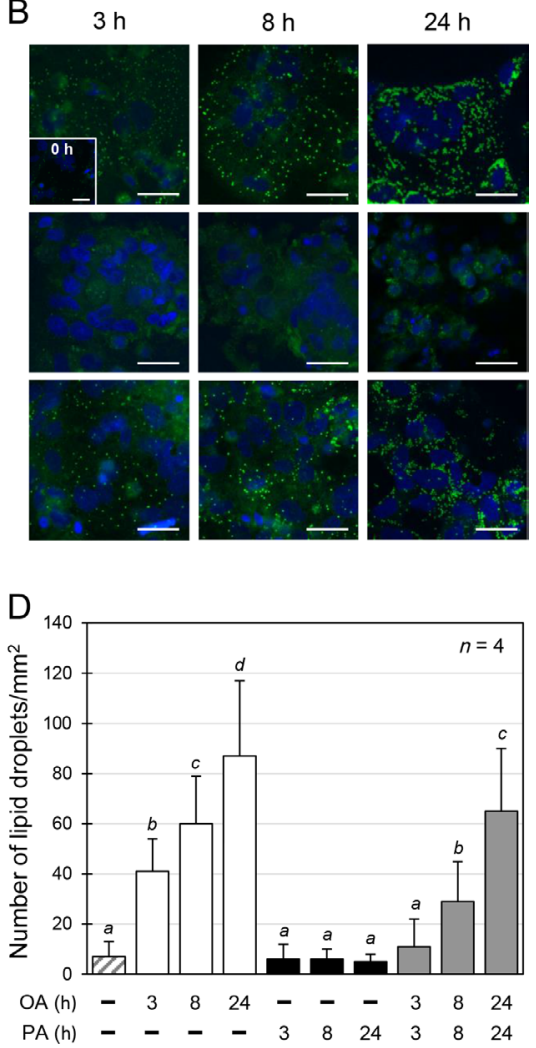

Figure 6 Free fatty acids affect lipid droplet formation. (A) Syncytiotrophoblasts were treated with oleate or palmitate at increasing concentrations or with equimolar concentrations of both lipids for $24 \mathrm{~h}$. (B) Syncytiotrophoblasts were treated with $200 \mu \mathrm{M}$ oleate, palmitate or $200 \mu \mathrm{M}$ each for the indicated times. (A and B) Lipid droplets were stained with BODIPY and DNA was stained with TOPRO3. Inset figure in top left image is control condition with no added lipid. Scale bar is $25 \mu \mathrm{m}$. (C and D) Quantified lipid droplets are expressed as number of lipid droplets per unit area of syncytiotrophoblast. Data are mean \pm S.D. with the number of primary cultures indicated by $n$.

Conditions with a common italicized letter do not differ as analyzed by one-way ANOVA with Bonferroni post hoc test $(P<0.05)$.
(Lager et al. 2014). Collectively, the data show that oleate and palmitate, as prominent dietary FFA, have divergent effects on the trophoblast when considered alone, yet the ratio of these FFA is likely the ultimate determinant of the effect on trophoblast function in vivo.

Palmitate, but not oleate, is also cytotoxic in several non-placental cell types (Cnop et al. 2001, Listenberger et al. 2001, Miller et al. 2005, Ricchi et al. 2009), but the effect of these lipids on the viability of human syncytiotrophoblasts has not been previously investigated. The question of lipotoxicity is physiologically relevant as pregnant, obese women have elevated serum levels of FFA (Chen et al. 2010b), and maternal blood exposes syncytiotrophoblasts to ambient FFA levels. Importantly, obesity by itself is a risk factor for placental dysfunction that increases the risk for stillbirth (Aune et al. 2014); yet, no placental histopathology is attributed to the phenotype of obesity, independent of other disease states. Our study suggests that the effects of excess palmitate ingestion could enhance damage to villous trophoblasts in vivo and, if unrepaired, villous trophoblast transport functions could suffer and not be able to sustain the needs of the fetus. This speculation offers a testable hypothesis that would predict an increase in expression of $\mathrm{CHOP}$ in placentas of obese patients that had adverse outcomes. On the other hand, oleate induction of fat storage in lipid droplets may avoid trophoblast lipotoxicity but excess nutrients may support fetal overgrowth with the accompanying risks of this condition. Importantly, we assayed trophoblasts for the effects of levels of fatty acids that are clearly within the range present in human serum. The $100 \mu \mathrm{M}$ palmitate, or oleate, approximates those found in lean, healthy pregnant women, whereas $200-400 \mu \mathrm{M}$ of these lipids are levels present in some obese pregnant individuals (Villa et al. 2009, Chen et al. $2010 b$ ). Clearly, the presence or absence of lipotoxicity in vivo will be modulated not only by the ratios of FFA but will be influenced by the other substrates present in vivo. For example, the toxic effects of saturated fats are exacerbated by exposure to elevated levels of glucose (El-Assaad et al. 2003, Prause et al. 2014).

We note that although it is possible that obesity is involved in ER-mediated lipotoxicity, it is unlikely the question is this simple. Notably, the effects of obesity on placental histopathology and function are poorly studied. One study compared placentas from women with high vs normal BMI (Higgins et al. 2013) found a modest, but significant, correlation of increased BMI with decreased trophoblast apoptosis. Moreover, Yung and coworkers (Yung et al. 2016) found no increase in placental ER stress in overweight women. Thus, the effects of obesity on placental ER stress, trophoblast apoptosis and placental function are as yet ill-defined and require further study. However, our data suggest that the most important factor in ER stress-mediated placental dysfunction may not be obesity per se but rather the ratios of saturated and unsaturated fatty acids. 
Thus, in future studies, although stratification by BMI may be useful, it may be even more important to stratify women also to the levels, types and (perhaps most importantly) to the relative ratios of circulating saturated and unsaturated fatty acids.

Brass and coworkers (Brass et al. 2013) showed that uptake of oleic acid was lower in villi of male offspring, but higher in female offspring, of obese women, compared to lean women. This result raises a limitation of our study, as we did not plan experiments to identify sex effects of FFA exposure of trophoblasts. We thus cannot state whether or not differential oleate uptake is influenced by sex of the trophoblasts studied. A second limitation is that we investigated the effect of elevated fatty acids on in vitro cultured primary syncytiotrophoblasts. Although we believe our model has the benefit of using primary cells, we have not shown any direct effects on human placental villi in situ. Notably, there is not yet a clear placental histopathologic correlate identified for women with obesity, although recent studies have investigated this question (Roberts et al. 2011, Huang et al. 2014, Kovo et al. 2015). What these studies reveal is the presence of an increase in frequency of maternal placental vascular lesions in placentas from obese women, compared to lean controls. Unfortunately, vascular lesions in the basal plate is a non-specific marker. Our study has identified potential molecular and cellular targets for comparing the histopathology of placentas from obese and lean pregnancies. Specifically, we propose villi from obese vs lean women should be characterized for differences in markers for apoptosis (cl-PARP and Cl-CYT18), ER stress (CHOP expression) and intracellular lipid accumulation (lipid droplet assessment). Such investigations may yield a more specific pathological correlate for signs of placental compromise in pregnancies of obese women.

\section{Declaration of interest}

The authors declare that there is no conflict of interest that could be perceived as prejudicing the impartiality of the research reported.

\section{Funding}

This work was supported by the BJH Foundation, the Department of Obstetrics and Gynecology at Washington University School of Medicine, St Louis, MO, Conselho Nacional de Desenvolvimento Científico e Tecnológico (CNPq) - Science Without Borders (200356/2014-3 to M. L. C.) and by Sao Paulo Research Foundation - (FAPESP - 2014/01925-0 to M. L. C.).

\section{Acknowledgements}

The authors thank Dr Deborah J Frank for critical reading of this manuscript.

\section{References}

Akazawa Y, Cazanave S, Mott JL, Elmi N, Bronk SF, Kohno S, Charlton MR \& Gores GJ 2010 Palmitoleate attenuates palmitate-induced Bim and PUMA up-regulation and hepatocyte lipoapoptosis. Journal of Hepatology 52 586-593. (doi:10.1016/j.jhep.2010.01.003)

American College of Obstetricians and Gynecologists 2013 ACOG Committee opinion no. 549: obesity in pregnancy. Obstetrics and Gynecology $121 \quad$ 213-217. (doi:10.1097/01. AOG.0000425667.10377.60)

Aune D, Saugstad OD, Henriksen T \& Tonstad S 2014 Maternal body mass index and the risk of fetal death, stillbirth, and infant death: a systematic review and meta-analysis. JAMA 311 1536-1546. (doi:10.1001/ jama.2014.2269)

Brass E, Hanson E \& O'Tierney-Ginn PF 2013 Placental oleic acid uptake is lower in male offspring of obese women. Placenta 34 503-509. (doi:10.1016/j.placenta.2013.03.009)

Chen B, Longtine MS, Sadovsky Y \& Nelson DM 2010a Hypoxia downregulates p53 but induces apoptosis and enhances expression of BAD in cultures of human syncytiotrophoblasts. American Journal of Physiology: Cell Physiology 299 C968-C976. (doi:10.1152/ ajpcell.00154.2010)

Chen X, Scholl TO, Leskiw M, Savaille J \& Stein TP $2010 b$ Differences in maternal circulating fatty acid composition and dietary fat intake in women with gestational diabetes mellitus or mild gestational hyperglycemia. Diabetes Care 33 2049-2054. (doi:10.2337/dc10-0693)

Chen B, Tuuli MG, Longtine MS, Shin JS, Lawrence R, Inder T \& Michael Nelson D 2012 Pomegranate juice and punicalagin attenuate oxidative stress and apoptosis in human placenta and in human placental trophoblasts. American Journal of Physiology: Endocrinology and Metabolism 302 E1142-E1152. (doi:10.1152/ ajpendo.00003.2012)

Chen B, Zaveri PG, Longtine MS \& Nelson DM 2015 N-myc downstreamregulated gene 1 (NDRG1) mediates pomegranate juice protection from apoptosis in hypoxic BeWo cells but not in primary human trophoblasts. Placenta 36 847-853. (doi:10.1016/j.placenta.2015.05.009)

Cnop M, Hannaert JC, Hoorens A, Eizirik DL \& Pipeleers DG 2001 Inverse relationship between cytotoxicity of free fatty acids in pancreatic islet cells and cellular triglyceride accumulation. Diabetes 50 1771-1777. (doi:10.2337/diabetes.50.8.1771)

Cunha DA, Hekerman P, Ladriere L, Bazarra-Castro A, Ortis F, Wakeham MC, Moore F, Rasschaert J, Cardozo AK, Bellomo E et al. 2008 Initiation and execution of lipotoxic ER stress in pancreatic beta-cells. Journal of Cell Science 121 2308-2318. (doi:10.1242/ jcs.026062)

Dufey E, Sepulveda D, Rojas-Rivera D \& Hetz C 2014 Cellular mechanisms of endoplasmic reticulum stress signaling in health and disease. 1. An overview. American Journal of Physiology: Cell Physiology 307 C582-C594. (doi:10.1152/ajpcell.00258.2014)

Egnatchik RA, Leamy AK, Jacobson DA, Shiota M \& Young JD 2014 ER calcium release promotes mitochondrial dysfunction and hepatic cell lipotoxicity in response to palmitate overload. Molecular Metabolism 3 544-553. (doi:10.1016/j.molmet.2014.05.004)

El-Assaad W, Buteau J, Peyot ML, Nolan C, Roduit R, Hardy S, Joly E, Dbaibo G, Rosenberg L \& Prentki M 2003 Saturated fatty acids synergize with elevated glucose to cause pancreatic beta-cell death. Endocrinology 144 4154-4163. (doi:10.1210/en.2003-0410)

Finnie JW 2001 Effect of tunicamycin on hepatocytes in vitro. Journal of Comparative Pathology 125 318-321. (doi:10.1053/jcpa.2001.0510)

Flegal KM, Carroll MD, Kit BK \& Ogden CL 2012 Prevalence of obesity and trends in the distribution of body mass index among US adults, 1999-2010. JAMA 307 491-497. (doi:10.1001/jama.2012.39)

Guo W, Wong S, Xie W, Lei T \& Luo Z 2007 Palmitate modulates intracellular signaling, induces endoplasmic reticulum stress, and causes apoptosis in mouse 3T3-L1 and rat primary preadipocytes. American Journal of Physiology: Endocrinology and Metabolism 293 E576-E586. (doi:10.1152/ajpendo.00523.2006)

Hetz C 2012 The unfolded protein response: controlling cell fate decisions under ER stress and beyond. Nature Reviews Molecular Cell Biology 13 89-102. (doi:10.1038/nrm3270)

Higgins L, Mills TA, Greenwood SL, Cowley EJ, Sibley CP \& Jones RL 2013 Maternal obesity and its effect on placental cell turnover. Journal of 
Maternal-Fetal and Neonatal Medicine 26 783-788. (doi:10.3109/147 67058.2012.760539)

Hockenbery DM, Oltvai ZN, Yin XM, Milliman CL \& Korsmeyer SJ 1993 $\mathrm{BCl}-2$ functions in an antioxidant pathway to prevent apoptosis. Cell 75 241-251. (doi:10.1016/0092-8674(93)80066-N)

Huang L, Liu J, Feng L, Chen Y, Zhang J \& Wang W 2014 Maternal prepregnancy obesity is associated with higher risk of placental pathological lesions. Placenta 35 563-569. (doi:10.1016/j. placenta.2014.05.006)

Karaskov E, Scott C, Zhang L, Teodoro T, Ravazzola M \& Volchuk A 2006 Chronic palmitate but not oleate exposure induces endoplasmic reticulum stress, which may contribute to INS-1 pancreatic beta-cell apoptosis. Endocrinology 147 3398-3407. (doi:10.1210/en.20051494)

Khaw KT, Friesen MD, Riboli E, Luben R \& Wareham N 2012 Plasma phospholipid fatty acid concentration and incident coronary heart disease in men and women: the EPIC-Norfolk prospective study. PLoS Medicine 9 e1001255. (doi:10.1371/journal.pmed.1001255)

Kovo M, Zion-Saukhanov E, Schreiber L, Mevorach N, Divon M, Ben-Haroush A \& Bar J 2015 The effect of maternal obesity on pregnancy outcome in correlation with placental pathology. Reproductive Sciences 22 1643-1648. (doi:10.1177/1933719115592712)

Kwon B, Lee HK \& Querfurth HW 2014 Oleate prevents palmitateinduced mitochondrial dysfunction, insulin resistance and inflammatory signaling in neuronal cells. Biochimica et Biophysica Acta 1843 1402-1413. (doi:10.1016/j.bbamcr.2014.04.004)

Lager S, Gaccioli F, Ramirez VI, Jones HN, Jansson T \& Powell TL 2013 Oleic acid stimulates system $\mathrm{A}$ amino acid transport in primary human trophoblast cells mediated by toll-like receptor 4. Journal of Lipid Research 54 725-733. (doi:10.1194/jIr.M033050)

Lager S, Jansson T \& Powell TL 2014 Differential regulation of placental amino acid transport by saturated and unsaturated fatty acids. American Journal of Physiology: Cell Physiology 307 C738-C744. (doi:10.1152/ ajpcell.00196.2014)

Lai E, Bikopoulos G, Wheeler MB, Rozakis-Adcock M \& Volchuk A 2008 Differential activation of ER stress and apoptosis in response to chronically elevated free fatty acids in pancreatic beta-cells. American Journal of Physiology: Endocrinology and Metabolism 294 E540-E550. (doi:10.1152/ajpendo.00478.2007)

Leamy AK, Egnatchik RA \& Young JD 2013 Molecular mechanisms and the role of saturated fatty acids in the progression of non-alcoholic fatty liver disease. Progress in Lipid Research 52 165-174. (doi:10.1016/j. plipres.2012.10.004)

Leamy AK, Egnatchik RA, Shiota M, Ivanova PT, Myers DS, Brown HA \& Young JD 2014 Enhanced synthesis of saturated phospholipids is associated with ER stress and lipotoxicity in palmitate treated hepatic cells. Journal of Lipid Research 55 1478-1488. (doi:10.1194/jlr. M050237)

Listenberger LL \& Brown DA 2007 Fluorescent detection of lipid droplets and associated proteins. Current Protocols in Cell Biology Chapter 24 Unit 24 22. (doi:10.1002/0471143030.cb2402s35)

Listenberger LL, Ory DS \& Schaffer JE 2001 Palmitate-induced apoptosis can occur through a ceramide-independent pathway. Journal of Biological Chemistry 276 14890-14895. (doi:10.1074/jbc.M010286200)

Listenberger LL, Han X, Lewis SE, Cases S, Farese RV Jr, Ory DS \& Schaffer JE 2003 Triglyceride accumulation protects against fatty acid-induced lipotoxicity. PNAS $\mathbf{1 0 0}$ 3077-3082. (doi:10.1073/ pnas.0630588100)

Lu J, Wang Q, Huang L, Dong H, Lin L, Lin N, Zheng F \& Tan J 2012 Palmitate causes endoplasmic reticulum stress and apoptosis in human mesenchymal stem cells: prevention by AMPK activator. Endocrinology 153 5275-5284. (doi:10.1210/en.2012-1418)

Mantzaris MD, Tsianos EV \& Galaris D 2011 Interruption of triacylglycerol synthesis in the endoplasmic reticulum is the initiating event for saturated fatty acid-induced lipotoxicity in liver cells. FEBS Journal 278 519-530. (doi:10.1111/j.1742-4658.2010.07972.x)

Marchi J, Berg M, Dencker A, Olander EK \& Begley C 2015 Risks associated with obesity in pregnancy, for the mother and baby: a systematic review of reviews. Obesity Reviews 16 621-638. (doi:10.1111/obr.12288)

Meller M, Vadachkoria S, Luthy DA \& Williams MA 2005 Evaluation of housekeeping genes in placental comparative expression studies. Placenta 26 601-607. (doi:10.1016/j.placenta.2004.09.009)
Micha R \& Mozaffarian D 2010 Saturated fat and cardiometabolic risk factors, coronary heart disease, stroke, and diabetes: a fresh look at the evidence. Lipids 45 893-905. (doi:10.1007/s11745-010-3393-4)

Miller TA, LeBrasseur NK, Cote GM, Trucillo MP, Pimentel DR, Ido Y, Ruderman NB \& Sawyer DB 2005 Oleate prevents palmitateinduced cytotoxic stress in cardiac myocytes. Biochemical and Biophysical Research Communications 336 309-315. (doi:10.1016/j. bbrc.2005.08.088)

Murthi P, Fitzpatrick E, Borg AJ, Donath S, Brennecke SP \& Kalionis B 2008 GAPDH, 18S rRNA and YWHAZ are suitable endogenous reference genes for relative gene expression studies in placental tissues from human idiopathic fetal growth restriction. Placenta 29 798-801. (doi:10.1016/j.placenta.2008.06.007)

Nelson SM, Matthews P \& Poston L 2010 Maternal metabolism and obesity: modifiable determinants of pregnancy outcome. Human Reproduction Update 16 255-275. (doi:10.1093/humupd/dmp050)

Nemcova-Furstova V, James RF \& Kovar J 2011 Inhibitory effect of unsaturated fatty acids on saturated fatty acid-induced apoptosis in human pancreatic beta-cells: activation of caspases and ER stress induction. Cellular Physiology and Biochemistry 27 525-538. (doi:10.1159/000329954)

Palomer X, Capdevila-Busquets E, Botteri G, Salvado L, Barroso E, Davidson MM, Michalik L, Wahli W \& Vazquez-Carrera M 2014 PPARbeta/delta attenuates palmitate-induced endoplasmic reticulum stress and induces autophagic markers in human cardiac cells. International Journal of Cardiology 174 110-118. (doi:10.1016/j. ijcard.2014.03.176)

Peng G, Li L, Liu Y, Pu J, Zhang S, Yu J, Zhao J \& Liu P 2011 Oleate blocks palmitate-induced abnormal lipid distribution, endoplasmic reticulum expansion and stress, and insulin resistance in skeletal muscle. Endocrinology 152 2206-2218. (doi:10.1210/en.2010-1369)

Pfaffenbach KT, Gentile CL, Nivala AM, Wang D, Wei Y \& Pagliassotti MJ 2010 Linking endoplasmic reticulum stress to cell death in hepatocytes: roles of C/EBP homologous protein and chemical chaperones in palmitate-mediated cell death. American Journal of Physiology: Endocrinology and Metabolism 298 E1027-E1035. (doi:10.1152/ ajpendo.00642.2009)

Pilz S, Scharnagl H, Tiran B, Seelhorst U, Wellnitz B, Boehm BO, Schaefer JR \& Marz W 2006 Free fatty acids are independently associated with all-cause and cardiovascular mortality in subjects with coronary artery disease. Journal of Clinical Endocrinology and Metabolism 91 2542-2547. (doi:10.1210/jc.2006-0195)

Poitout V, Amyot J, Semache M, Zarrouki B, Hagman D \& Fontes G 2010 Glucolipotoxicity of the pancreatic beta cell. Biochimica et Biophysica Acta 1801 289-298. (doi:10.1016/j.bbalip.2009.08.006)

Prause M, Christensen DP, Billestrup N \& Mandrup-Poulsen T 2014 JNK1 protects against glucolipotoxicity-mediated beta-cell apoptosis. PLOS ONE 9 e87067. (doi:10.1371/journal.pone.0087067)

Ricchi M, Odoardi MR, Carulli L, Anzivino C, Ballestri S, Pinetti A, Fantoni LI, Marra F, Bertolotti M, Banni S et al. 2009 Differential effect of oleic and palmitic acid on lipid accumulation and apoptosis in cultured hepatocytes. Journal of Gastroenterology and Hepatology 24 830-840. (doi:10.1111/j.1440-1746.2008.05733.x)

Roberts KA, Riley SC, Reynolds RM, Barr S, Evans M, Statham A, Hor K, Jabbour HN, Norman JE \& Denison FC 2011 Placental structure and inflammation in pregnancies associated with obesity. Placenta 32 247-254. (doi:10.1016/j.placenta.2010.12.023)

Schilling JD, Machkovech HM, He L, Diwan A \& Schaffer JE 2013 TLR4 activation under lipotoxic conditions leads to synergistic macrophage cell death through a TRIF-dependent pathway. Journal of Immunology 190 1285-1296. (doi:10.4049/jimmunol.1202208)

Schmittgen TD \& Livak KJ 2008 Analyzing real-time PCR data by the comparative C(T) method. Nature Protocols 3 1101-1108. (doi:10.1038/ nprot.2008.73)

Sommerweiss D, Gorski T, Richter S, Garten A \& Kiess W 2013 Oleate rescues INS-1E beta-cells from palmitate-induced apoptosis by preventing activation of the unfolded protein response. Biochemical and Biophysical Research Communications 441 770-776. (doi:10.1016/j. bbrc.2013.10.130)

Soumura M, Kume S, Isshiki K, Takeda N, Araki S, Tanaka Y, Sugimoto T, Chin-Kanasaki M, Nishio Y, Haneda M et al. 2010 Oleate and eicosapentaenoic acid attenuate palmitate-induced inflammation 
and apoptosis in renal proximal tubular cell. Biochemical and Biophysical Research Communications 402 265-271. (doi:10.1016/j. bbrc.2010.10.012)

Tabas I \& Ron D 2011 Integrating the mechanisms of apoptosis induced by endoplasmic reticulum stress. Nature Cell Biology 13 184-190. (doi:10.1038/ncb0311-184)

Thorn K \& Bergsten P 2010 Fatty acid-induced oxidation and triglyceride formation is higher in insulin-producing MIN6 cells exposed to oleate compared to palmitate. Journal of Cellular Biochemistry 111 497-507. (doi:10.1002/jcb.22734)

Urra H, Dufey E, Lisbona F, Rojas-Rivera D \& Hetz C 2013 When ER stress reaches a dead end. Biochimica et Biophysica Acta 1833 3507-3517. (doi:10.1016/j.bbamcr.2013.07.024)

van Dijk SJ, Feskens EJ, Bos MB, Hoelen DW, Heijligenberg R, Bromhaar MG, de Groot LC, de Vries JH, Muller M \& Afman LA 2009 A saturated fatty acid-rich diet induces an obesity-linked proinflammatory gene expression profile in adipose tissue of subjects at risk of metabolic syndrome. American Journal of Clinical Nutrition 90 1656-1664. (doi:10.3945/ajcn.2009.27792)

Villa PM, Laivuori H, Kajantie E \& Kaaja R 2009 Free fatty acid profiles in preeclampsia. Prostaglandins Leukot Essent Fatty Acids 81 17-21. (doi:10.1016/j.plefa.2009.05.002)

Wang Y, Chen B, Longtine MS \& Nelson DM 2016 Punicalagin promotes autophagy to protect primary human syncytiotrophoblasts from apoptosis. Reproduction 151 97-104. (doi:10.1530/REP-15-0287)

Wei Y, Wang D, Topczewski F \& Pagliassotti MJ 2006 Saturated fatty acids induce endoplasmic reticulum stress and apoptosis independently of ceramide in liver cells. American Journal of Physiology: Endocrinology and Metabolism 291 E275-E281. (doi:10.1152/ajpendo.00644.2005)

Xu C, Bailly-Maitre B \& Reed JC 2005 Endoplasmic reticulum stress: cell life and death decisions. Journal of Clinical Investigation $\mathbf{1 1 5}$ 2656-2664. (doi:10.1172/JCl26373)
Yung HW, Calabrese S, Hynx D, Hemmings BA, Cetin I, Charnock-Jones DS \& Burton GJ 2008 Evidence of placental translation inhibition and endoplasmic reticulum stress in the etiology of human intrauterine growth restriction. American Journal of Pathology 173 451-462. (doi:10.2353/ajpath.2008.071193)

Yung HW, Cox M, Tissot van Patot M \& Burton GJ 2012a Evidence of endoplasmic reticulum stress and protein synthesis inhibition in the placenta of non-native women at high altitude. FASEB Journal 26 1970-1981. (doi:10.1096/fj.11-190082)

Yung HW, Hemberger M, Watson ED, Senner CE, Jones CP, Kaufman RJ, Charnock-Jones DS \& Burton GJ 2012b Endoplasmic reticulum stress disrupts placental morphogenesis: implications for human intrauterine growth restriction. Journal of Pathology 228 554-564. (doi:10.1002/ path.4068)

Yung HW, Alnaes-Katjavivi P, Jones CJ, El-Bacha T, Golic M, Staff AC \& Burton GJ 2016 Placental endoplasmic reticulum stress in gestational diabetes: the potential for therapeutic intervention with chemical chaperones and antioxidants. Diabetologia 59 2240-2250. (doi:10.1007/ s00125-016-4040-2)

Yuzefovych L, Wilson G \& Rachek L 2010 Different effects of oleate vs. palmitate on mitochondrial function, apoptosis, and insulin signaling in L6 skeletal muscle cells: role of oxidative stress. American Journal of Physiology: Endocrinology and Metabolism 299 E1096-E1105. (doi:10.1152/ajpendo.00238.2010)

Received 19 October 2016

First decision 14 November 2016

Revised manuscript received 2 December 2016

Accepted 3 January 2017 